\title{
Electrophysiological evidence of perceived sexual attractiveness for human female bodies varying in waist-to-hip ratio
}

\author{
Marzia Del Zotto ${ }^{1,3}$ - Alan J. Pegna ${ }^{1,2}$
}

Published online: 17 March 2017

(C) Psychonomic Society, Inc. 2017

\begin{abstract}
The dynamics of brain activation reflecting attractiveness in humans are unclear. Among the different features affecting attractiveness of the female body, the waist-to-hip ratio (WHR) is considered to be crucial. To date, however, no eventrelated potential (ERP) study has addressed the question of its associated pattern of brain activation. We carried out two different experiments: (a) a behavioural study, to judge the level of attractiveness of female realistic models depicting 4 different WHRs $(0.6,0.7,0.8,0.9)$ with and without clothes; (b) an EEG paradigm, to record brain activity while participants (heterosexual men and women) viewed these same models. Behavioural results showed that WHRs of 0.7 were considered more attractive than the others. ERP analyses revealed a different pattern of activation for male and female viewers. The 0.7 ratio elicited greater positivity at the $\mathrm{P} 1$ level in male viewers but not females. Naked bodies increased the N190 in both groups and peaked earlier for the 0.7 ratio in the male viewers. Finally, the late positive component (LPC) was found to be greater in male than in female viewers and was globally more marked for naked bodies as well as WHRs of 0.7 in both groups of viewers. These results provide the first electrophysiological evidence of specific
\end{abstract}

Marzia Del Zotto

marziadz@gmail.com

$\triangle \quad$ Alan J. Pegna

a.pegna@uq.edu.au

1 Laboratory of Experimental Neuropsychology, Faculty of Psychology and Educational Sciences, University of Geneva, 1205 Geneva, Switzerland

2 School of Psychology, The University of Queensland, Brisbane, Qld 4072, Australia

3 Department of Radiology and Medical Informatics, Division of Medical Information Sciences, University Hospitals of Geneva, CH-1211 Geneva, Switzerland time periods linked to the processing of a body feature denoting attractiveness and therefore playing a role in mate choice.

Keywords Waist-to-hip ratio (WHR) - P1 · N190 · LPC . Appetitive stimuli $\cdot$ Biologically relevant stimuli $\cdot$ Sexual behaviour $\cdot$ Body $\cdot$ Attractiveness

Physical attractiveness, which underlies mate selection, is determined by different characteristics of the face and body. Regarding faces, it has been ascertained that more symmetrical stimuli increase attractiveness (Gangestad, Thornhill, \& Yeo, 1994; Grammer \& Thornhill, 1994; Mealey, Bridgstock, \& Townsend, 1999; Perrett et al., 1999; PentonVoak et al., 2001), as do those that are closer to the average of the population (Halberstadt \& Rhodes, 2000; Langlois \& Roggman, 1990). Additionally, sexually dimorphic traits such as full lips in women or large jaws in men, which determine the masculinity or femininity of a face, also affect perceived attractiveness (Perrett et al., 1998). As far as female bodies are concerned, features such as waist-to-hip ratio (WHR), body mass index (BMI), and breast size have all been found identified as crucial factors, influencing attractiveness (Currie \& Little, 2009; Dixson, Grimshaw, Linklater, \& Dixson, 2010; Swami \& Furnham, 2009; Swami \& Tovée, 2006).

BMI is defined as the weight divided by the height $(\mathrm{kg} / \mathrm{m})$ (Tovée \& Cornelissen, 2001) and involves overall body fat, independently of its localization (Cornelissen, Hancock, Kiviniemi, George, \& Tovée, 2009) and it has been proven that a low BMI has a high impact on health and on the reproductive potential of women (Swami \& Tovée, 2005) as well as determining attractiveness, possibly to a greater extent than WHR (Tovée, Maisey, Emery, \& Cornelissen, 1999). WHR is defined as the ratio of the width of the waist (i.e. the narrowest portion between the ribs and the iliac crest) and 
the width of the hips (i.e. the greatest protrusion at the level of the buttocks; Furnham, Mistry, \& McClelland, 2004; Tovée \& Cornelissen 2001). It is also considered as a crucial predictor of physical attractiveness and seems to reflect female fertility and health (Singh, 2002) as well as providing reliable indication of fat distribution (Dixson, Dixson, Li, \& Anderson, 2007).

\section{WHRs and fertility}

Findings in the literature show that the WHR of a healthy woman during the fertile period of the lifespan is between 0.67 and 0.8 , while it is between 0.85 and 0.95 in healthy men (Henss, 1995). A different concentration of hormones between males and females causes a sexual dimorphism that leads to differences in body shape between genders, as demonstrated in a study by Pazhoohi and Liddle (2012). Results showed that the female body shape had an average WHR of 0.73 , which was much lower than the male body shape that had a WHR of 0.87. In this sense, specific WHRs can be perceived as a gender cue, in the absence of other indices. Remarkably, a lower WHR (i.e. close to 0.7) represents the optimal fat distribution for female fertility (Singh, 2002; Swami \& Tovée, 2005) and is a marker of a regular ovulation cycle, as well as of sufficient storage of omega-3, essential for the neural development of the foetus (Dixson et al., 2010). By contrast, it is inversely related to pregnancy (Furnham et al., 2004). WHR is a dimorphic trait differentiating genders, as it reflects the effects of sex hormones that regulate fat deposits. Indeed, oestrogen stimulates fat deposits in the thighs and buttocks, but inhibits it in the abdominal area; conversely, testosterone acts in the opposite way. Thus, women present a lower WHR compared to men, especially after puberty, because they possess more fat in their hips and less in their abdomen during the most fertile period of reproduction. During and after menopause, female WHRs change again, shifting closer to those of men, due to decreasing oestrogen levels (Cremonini et al., 2013). Women taking oestrogenenhancing medication after menopause have relatively lower WHRs than women avoiding this type of medication. Basically, small waist size is associated with a high level of oestrogen and progesterone, predictors of the reproductive potential; while testosterone promotes central obesity (Bohler, Mokshagundam, \& Winters, 2010). In this sense, WHR is thought to be a reliable cue of oestrogen level (Dixson et al., 2011; Jasienska, Ziomkiewicz, Ellison, Lipson, \& Thune, 2004). Indeed, Jokela (2009) found that the more attractive women had a higher reproductive success and more children. Interestingly, female facial attractiveness has also been linked to estimates of fertility (Roberts et al., 2004) and to higher levels of sex hormones (Probst, Bobst, \&
Lobmaier, 2016; Puts et al., 2013), in addition to BMI (Han, Hahn, Fisher, Debruine, \& Jones, 2016).

Overall, body fat affects WHR, especially in low or high values of BMI; however both BMI and WHR are usually measured in order to accurately assess effect sizes of both aspects (Singh, 2002).

\section{WHRs and attractiveness}

Some authors argue that WHR may be one of the first filters in the evaluation of female bodies, used unconsciously by heterosexual men. For instance, using eye-tracking technique, Dixson and colleagues (2011) explored the frequency of visual fixations when men looked at front view photographs of naked female bodies with two different WHRs (0.7 vs. 0.9) and three breasts sizes (small, medium, and large). The results showed that the earliest visual fixation occurring within $200 \mathrm{~ms}$ and targeted the breasts or the waist, compared to the lower part of the body and the face. However, men rapidly rated the 0.7 WHR as most attractive independently of breast size, even though they spent more time looking at the breasts. This study seems to confirm that the WHR is a key feature in the appraisal of physical attractiveness of female bodies by male observers.

In one of the first studies on WHR preference (Singh, 1993), participants were asked to rate the physical attractiveness, as well as other characteristics of bodies (e.g. good health, youthful looking, desire for children, ability to have children) on a scale from 1 (most attractive) to 12 (least attractive). Stimuli consisted of line drawings combing three levels of BMI (underweight vs. normal vs. overweight) and four levels of WHR ( 0.7 vs. 0.8 vs. 0.9 vs. 1.0$)$, produced by changing waist size only. Results revealed that men considered the 0.7 WHR in the normal weight condition as the healthiest, the youngest, and the most attractive, followed by 0.8, 0.9 and finally 1.0. However, using the same stimuli, Henss (1995) found that 0.8 was considered more attractive than 0.7 , although post hoc comparisons showed that WHRs of $0.7,0.8$ and 0.9 were not significantly different in terms of their attractiveness rating. Several years later, using front view photos of women wearing swimsuits, Henss (2000) again showed that a lower WHR was preferred to a higher one, consistent with other reports (Furnham, Petrides, Constantinides, 2005; Singh, 1993; Singh \& Young, 1995). In particular, they showed that WHRs of 0.7 in bodies of normal weight are considered the healthiest and the most attractive, compared to the other WHRs. All in all, findings in literature provide consistent evidence of a preference for a low WHR (i.e. 0.7), despite methodological differences exist between studies concerning the stimuli and rating scales used. 


\section{Cultural influences}

Although it has been suggested that men may universally prefer women with a low WHR (e.g. Singh, 1993), variations may arise depending on the cultural background. Indeed, several studies have shown a significant association between country and WHR preference. For instance, in New Zealand a ratio of 0.7 was evaluated as the most sexually attractive (Dixson, Dixson, Bishop, \& Parish, 2009), while in California as well as in China, preference was given to 0.6 (Dixson, Dixson, Li, \& Anderson, 2007; Dixson et al. 2010). In another investigation (Swami, Caprario, Tovée, \& Furnham, 2006) carried out in industrialized societies (e.g. Britain and Japan), front view pictures of women with lower WHRs, like 0.6 and 0.7 , were again considered the most goodlooking, probably also due to media influence. Interestingly, Dixson, Dixson, Morgan, and Anderson (2007) found that women from Cameroon with ratios of 0.8 , were preferred to the lower WHRs, and in more primitive foraging societies such as the Hadza community in Tanzania, Marlowe and Wetsman (2001) found that the male members of hunter-gatherer tribes preferred the 0.9 ratio to lower WHRs.

Different factors can explain these cultural variations in preferences, including (a) local conditions, (b) media influence, and (c) type of relationship. What people mostly see since their early life is internalized and modulates the perception of body shape, image, and weight (Swami, Neto, Tovée, $\&$ Furnham, 2007). Thus, the WHR preference may correspond to the one of young women in each specific population (Marlowe, Apicella, \& Reed, 2005). Nevertheless, it should be emphasised that Western media have strongly influenced the ideal prototype of a human body (Singh, 2002), favouring an "ideal" prototype of human bodies at particularly low ratios (Singh, 2002). This may condition the perception of bodies and fashion during such periods, reinforcing what people usually see in their everyday life from a very early age (Swami et al., 2007). Evidence for this comes from studies showing for example that men from a tribe living in a natural reserve in Peru changed their preference after 30 years outside the reserve, under the Western media influence (Yu \& Shepard, 1998).

The fact that preferences can be modified according to exposition during childhood or the cultural background opens the possibility for an alternate mechanism at the root of attractiveness. This view, emerging from studies on facial attractiveness, holds that attractiveness is related to the averageness of a stimulus, or its prototypicality (Langlois \& Roggman, 1990). Indeed, these authors found that the average face is judged as more attractive than any of its individual exemplars and consequently argued that preference for an exemplar is likely determined by its proximity to the mean, or prototype of its category. In an electromyographic investigation, in which the activity of the zygomatus major was used to index attractiveness, Principe and Langlois (2012) showed that, after repeated exposure to strongly morphed human-chimpanzee faces, an increased preference was observed for intermediately morphed human-chimp faces, which gave rise to higher explicit ratings of attractiveness. This was not observed in control participants who were presented with nonmorphed human or chimpanzee faces. The authors suggested that experience with the morphed faces shifted the central tendency closer to chimpanzee faces, producing a sort of "recalibration" of the average exemplar closer to intermediate human-chimp faces, and consequently produced a shift in perceived attractiveness. Other reports have extended these findings to nonface stimuli, such as birds, fish and automobiles (Halberstadt \& Rhodes, 2003) or dot patterns (Winkielman, Halberstadt, Fazendeiro, \& Catty, 2006). The fact that a preference for prototypes is observed even for stimuli unrelated to mate selection suggests that the attractiveness of faces and bodies might not rely on a mechanism evaluating health and reproductive fitness, but rather on a more general one that computes a cognitive average and leads to a preference for exemplars that are closer to the prototypical representation.

\section{Neuroimaging findings}

Perception of faces and bodies are known to affect different specialized brain occipito-temporo-parietal pathways (Peelen \& Downing 2007; Schwarzlose, Baker, \& Kanwisher, 2005), and the attractiveness of both these categories has been shown to activate regions involved in reward networks, corresponding to the orbito-frontal cortex (OFC) (Aharon et al., 2001; Kedia, Mussweiler, Mullins, \& Linden, 2014; Winston, O’Doherty, Kilner, Perrett, \& Dolan, 2007). This specific area receives the majority of its visual input from the ventral stream and plays a fundamental role in the reinforcement mechanism for the cerebral reward centres (Rolls \& Grabenhorst, 2008). Attractive WHRs can also increase the neural activity in the OFC and in the nucleus accumbens, both included in reward circuits; whereas modifications in BMI modulates primarily the visual cortical areas (Platek \& Singh, 2010; Spicer \& Platek, 2010). By opposition, Holliday and colleagues (2011) found that BMI was more correlated with attractiveness judgments than WHR and activated higher cortical visual areas and reward centres. No change in BOLD signal was observed for WHR variations; but the lack of effect here was likely due to the very restrictive range of WHRs used (between 0.65 and 0.77 ).

From an electrophysiological perspective, event-related potential findings have shown that a posterior negative 
deflection, the N190, is category-sensitive to human bodies. This component arises over the posterior scalp at $190 \mathrm{~ms}$ and is akin to the N170 observed for faces (Thierry et al., 2006), as it is sensitive to bodies and shows an inversion effect (Stekelenburg \& Gelder, 2004). However, to our knowledge, no electrophysiological studies have addressed visual processing of the WHR to date.

In this study, we present the first electrophysiological investigation of WHR processing of images of realistic human female bodies. The aims of this study are threefold:

1. To establish if and how the WHR can affect the attractiveness of female bodies in male and female participants.

2. To analyse the temporal processing and electrophysiological disparities of different WHRs, without voluntary attention, in heterosexual man compared to heterosexual woman.

3. To verify if the WHR is a biologically relevant visual cue that can be processed automatically.

We performed two different experiments. In an initial behavioural rating task, female models with four different WHRs $(0.6,0.7,0.8$, and 0.9) were presented, either naked or clothed, and participants were asked to assess their attractiveness on a Likert scale. The second task included ERP measures and required indirect processing of the four WHRs. Both experiments included heterosexual men and women to test possible gender differences in the evaluation of attractiveness.

\section{Method}

\section{Behavioural study}

\section{Participants}

Forty healthy adults ( 20 men and 20 women), between 19 and 45 years of age, took part in the attractiveness rating task. Participants were predominantly right-handed (right-handed $n=36$; left-handed $n=2$; ambidextrous $n=2$ ), with normal or corrected-to-normal vision (Oldfield, 1971). They had no self-declared history of neurological or psychiatric disorder, and, in particular, declared no eating disorders or weight dysfunctions (Cornelissen et al., 2009).

The investigation was approved by our local ethics committee. Volunteers gave their written informed consent before contributing to the study. Prior to inclusion, we administered the 7 point Kinsey Scale Orientation Questionnaire (Kinsey, Pomeroy, \& Martin, 2003) to assess the sexual orientation of each participant. Participants were considered heterosexual if they scored 0 or 1 (36 with score 0 and 4 with score 1 , mean score 0.1 ).
Apparatus and stimuli

One hundred and ninety-two coloured images of $265 \times 756$ pixels $(7 \times 20 \mathrm{~cm})$ representing entire female bodies in a neutral static position were created using N-sided Quidam 3.1.5 (www.n-sided.com), a software dedicated to professional game developers. This software allowed us to generate realistic female bodies by changing size, skin and hair colour, and clothes. We created 12 different realistic models under different conditions: (a) clothed and naked, (b) frontal and posterior view, (c) four waist-to-hip ratios (small = 0.6 ; medium $=0.7 ;$ large $=0.8$; extra-large $=0.9)$, for a total of 16 conditions $(2$ clothes $\times 2$ perspectives $\times 4$ WHRs). Thus, each condition comprised a total of 192 stimuli. Skin colour was varied from dark (African) to light (Caucasian) to match the variations in light intensity produced by clothing. Additionally, all faces were manually blurred using Adobe Photoshop 6.0 to avoid an explicit influence of facial and expression features on the body processing. Examples of the stimuli are presented in Fig. 1a.

The WHRs were calculated by dividing the width of the waist by that of the hips (see Fig. 1b). The realistic female bodies had an apparent average BMI, that is, were neither underweight, nor overweight. Stimuli were identical with respect to size in all experimental conditions. Luminance was adjusted and controlled using ImageJ (http://rsbweb.nih.gov/ ij/index.html) and Adobe Photoshop 6.0 software. A statistical comparison of pixel intensity across conditions confirmed the absence of any significant difference across conditions.

\section{Experimental procedure}

Participants were asked to judge the attractiveness of the 192 pictures of female bodies on a continuous analogical scale, represented by a horizontal line that appeared under the stimulus, indicating a 5 -point Likert scale $(1=$ not at all; $2=a$ little; $3=$ somewhat $; 4=$ very $; 5=$ extremely).

Stimuli were presented in a random order at the centre of the screen. Participants indicated the degree of attractiveness of every single model by placing the mouse (cursor) on the black horizontal line appearing below the picture. The vertical red line indicated the localization of the cursor on the horizontal line and a corresponding numeric value, between 0 (unattractive) and 100 (extremely attractive), was recorded. After the instructions and before starting the rating task, some examples were presented to ensure that participants had fully understood how to perform the task properly (for an example, see Fig. 2).

\section{Behavioural data analysis}

Behavioural data were collected using E-Prime 2.0 (www. pstnet.com/eprime) and analysed using Statistica (http:// 


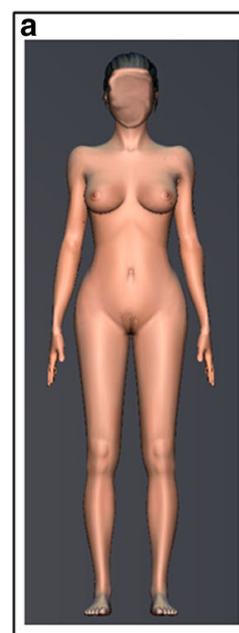

0.6

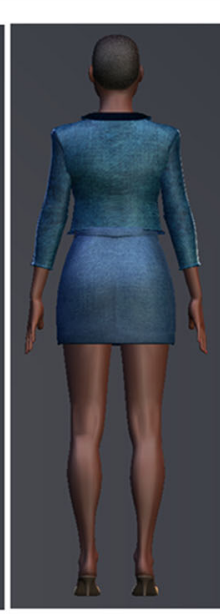

0.7

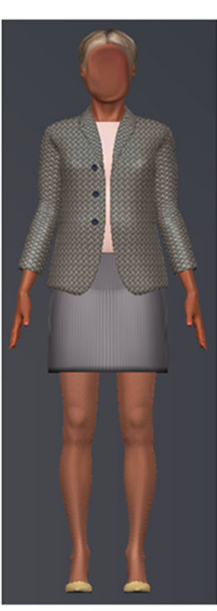

0.8
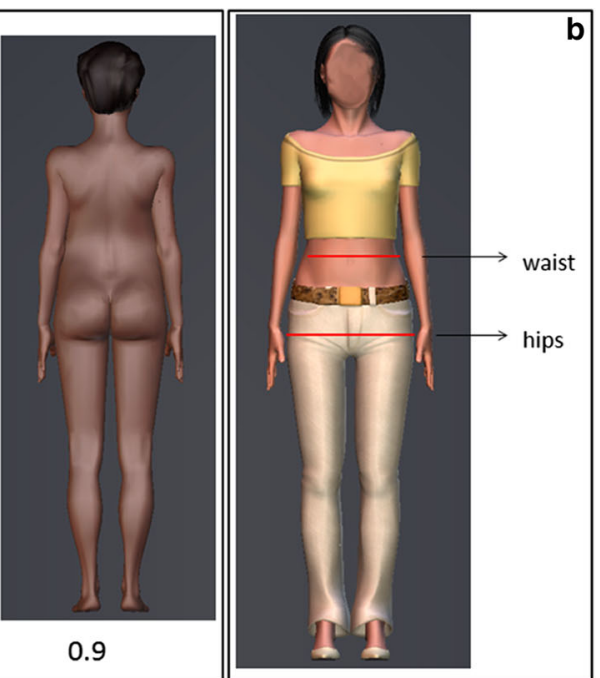

Fig. 1 a Different categories of stimuli depicting four WHRs $(0.6,0.7,0.8,0.9)$ in dressed and naked models, presented in a posterior and frontal view. $\mathbf{b}$ Waist-to-hip ratio was calculated by dividing the width at the waist with the width at the hips

www.statsoft.com/). A mixed design analyses of variance (ANOVA) was computed using participant gender (group: male or female) as a between-subjects measure, and nudity (clothed vs. naked bodies), view (front and back), and WHR (waist-to-hip-ratios: 0.6, 0.7, 0.8, 0.9) as repeated measures. Greenhouse-Geisser corrections were applied to correct for violations of sphericity and post hoc comparisons were performed using a Fisher LSD test (uncorrected). We reported measures of effect size (partial $\eta^{2}$ ) in addition to probability values.

\section{Electrophysiological study}

\section{Participants}

ERPs (event-related potentials) were recorded from 24 healthy adult volunteers who had not participated in the behavioural task ( 12 men and 12 women; mean age $=25.6$ years). Four participants (two men and two women) were excluded during the ERP analyses from the experimental sample due to excessive artefacts. Participants received $30 \mathrm{CHF}$ for their

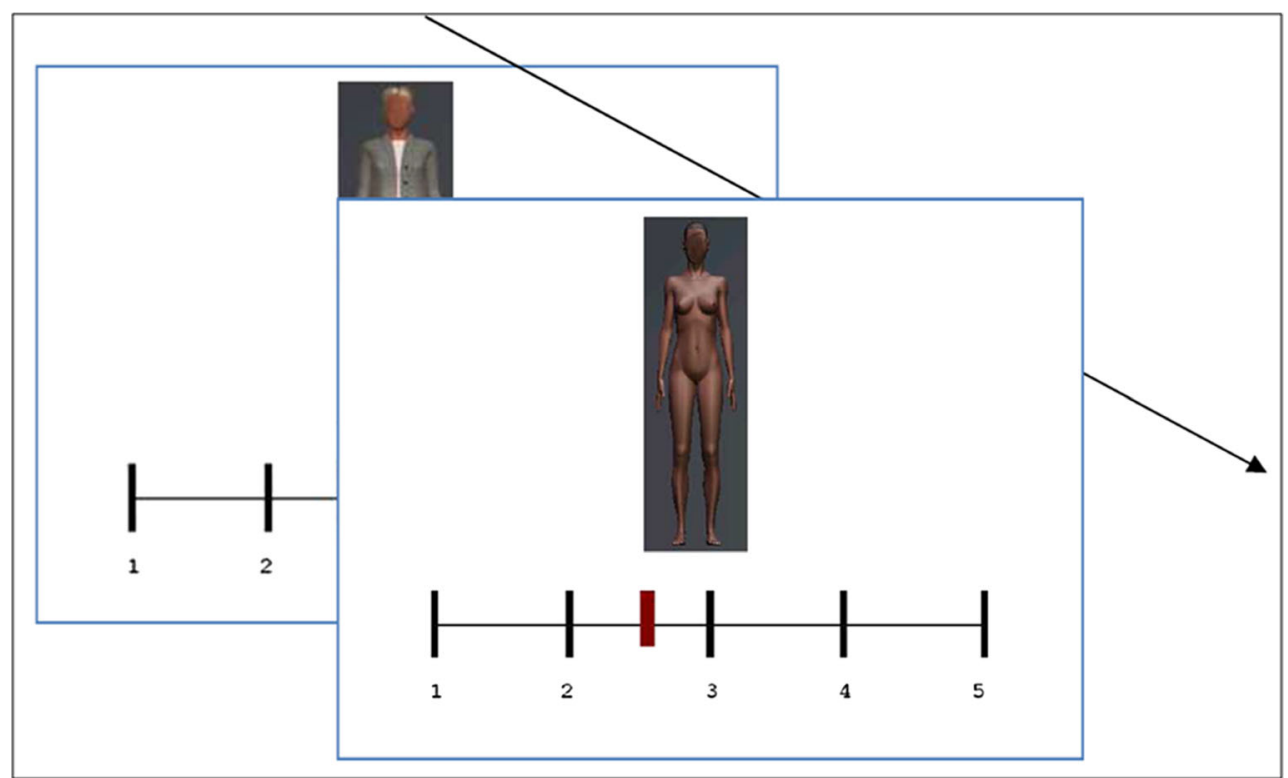

Fig. 2 Rating task procedure: Participants had to judge the attractiveness of each female model by placing the cursor (mouse) on a horizontal line, representing a continuous analogical 5 -point Likert scale $(1=$ not at all; 2
$=$ a little $; 3=$ somewhat $; 4=$ very $; 5=$ extremely). Based on the position of the cursor, the E-Prime software recorded the corresponding discrete value between 0 (unattractive) and 100 (extremely attractive) 
contribution and were not informed about the goal of the study beforehand. Eighteen of them reported that they were righthanded $(n=18)$ with a laterality quotient above $0(\min =26$, $\max =100)$, and only two participants were left-handed with a laterality quotient below 0 (-72 and -80$)$, as measured on the Oldfield-Edinburgh scale (Oldfield, 1971). Participants gave their written informed consent prior to the procedure. All had corrected-to-normal vision. As in the behavioural experiment, the main criterion of inclusion/exclusion was represented by the sexual orientation test. Based on the 7 point Kinsey Scale Orientation Questionnaire (Kinsey et al., 2003), all 20 participants were heterosexual.

\section{Apparatus and stimuli}

Experimental sessions took place in an electrically and acoustically isolated room, where participants were comfortably seated at a distance of $114 \mathrm{~cm}$ from a 17-in. display (resolution: $1024 \times 768$, refreshing rate: $60 \mathrm{~Hz}$ ). The stimuli included the same female bodies as in the behavioural study. At this distance, they subtended a visual angle of $3.5^{\circ}$ on the horizontal axis by $10^{\circ}$ on the vertical axis.

In this second study, participants performed an oddball task in which they were asked to respond to infrequent targets consisting either of clothed male bodies or pseudoanimals (also created using Quidam 3.1.5 software), depending on the session. They were asked to pay attention and to respond manually to targets by pressing a key with the index finger of the left or right hand. Response hand was counterbalanced across trails, with half of the subjects answering with the right index.

The experiment consisted of eight blocks of 192 trials presenting female bodies (12 different models $\times 16$ conditions) and 21 trials presenting the target (pseudo animals or clothed males). This yielded a total of 96 trials for every female body category. In half the blocks, targets consisted of pseudoanimals, while in the other half, the targets were realistic pictures of men. The order of the blocks was randomized across subjects and target categories. The stimuli were presented for $250 \mathrm{~ms}$, followed by a fixation cross, with an interstimulus interval (ISI) varying randomly between 1,000 and 1,200 ms.

\section{EEG recording and processing}

Continuous EEG was recorded at a sampling rate of 2,048 Hz, using the 128-channel BioSemi Active Two system (Biosemi Inc, Amsterdam, Netherlands, http://www.biosemi.com/ products.htm) and five external electrodes to detect eye movements (see Fig. 3). The signal was bandpass filtered online between $0.1 \mathrm{~Hz}$ and $100 \mathrm{~Hz}$, using a Common Mode Sense (CMS) of two electrodes located over the vertex as references. Impedances were checked and maintained below $20 \mathrm{k} \Omega$ during all the recording session. Participants were instructed to fixate the centre of the screen and to avoid any eye or body movements during the experimental EEG session. The EEG was down sampled to $512 \mathrm{~Hz}$, filtered off-line from 0.09 to $50 \mathrm{~Hz}$, and recalculated against the average reference, using the EEG processing software Cartool (www.fbmlab. com/cartool-software/). EEG was epoched offline from $100 \mathrm{~ms}$ before to $1,000 \mathrm{~ms}$ after the onset of the stimulus. Separate epochs were computed and averaged for each of the 16 female body categories and were baseline corrected using a prestimulus interval of $100 \mathrm{~ms}$ prior to the onset of the stimulus. Epochs contaminated by blinks, eye movements, or other artefacts (EEG sweeps with amplitudes exceeding $\pm 100 \mu \mathrm{V}$ ) as well as incorrect behavioural responses (false alarms) were excluded before the averaging procedure. Remaining artefacts were manually rejected upon visual inspection. ERP peak analyses were computed using Brain Vision Analyzer software (Brain Products $\mathrm{GmbH}$, München, Germany, http://www.brainproducts.com/index.php).

\section{ERP data analysis}

Based on visual observation of the maximum ERP effects, two ROIs were created, one on the left (PO7, $\mathrm{A} 11, \mathrm{~A} 12)$ and the other on the right (PO8, B8, B9) hemisphere, for the P1, the $\mathrm{N} 190$ and the P2 components. The peak amplitude was computed within 120 $160 \mathrm{~ms}, 160-220 \mathrm{~ms}$, and $250-310 \mathrm{~ms}$ time windows (see Fig. 3). The late positive component (LPC) was computed on a central ROI composed of 3 electrodes $(\mathrm{A} 1=\mathrm{Cz}, \mathrm{A} 2$ and $\mathrm{A} 3$ as shown in Fig. 3$)$ as the mean amplitude between $300-450 \mathrm{~ms}$, during the period where the effect was maximal.

The peak amplitudes and the latency values of P1, N1, and P2 ERPs were compared using a 2 (group: male or female) $\times 2$ (nudity: clothed or naked) $\times 2$ (view: front or back) $\times 4$ (WHRs: $0.6,0.7,0.8,0.9) \times 2$ (ROI: left or right) mixed-effects ANOVA. For the LPC, only one ROI was used so this level not present in the ANOVA. Additionally, post hoc comparisons were performed using the Fisher LSD test (uncorrected). GreenhouseGeisser corrections were applied to correct for violations of sphericity. We reported measures of effect size (partial $\eta^{2}$ ) in addition to probability values. All the significant results are summarised in the Table 1.

\section{Results}

\section{Behavioural study}

Ratings did not differ between the male and the female group. The main effects of nudity, $F(1,38)=6.43, M S E$ $=275, \varepsilon=1, p<.02, \eta_{\mathrm{p}}{ }^{2}=.15$, and view, $\mathrm{F}(1,38)=$ 


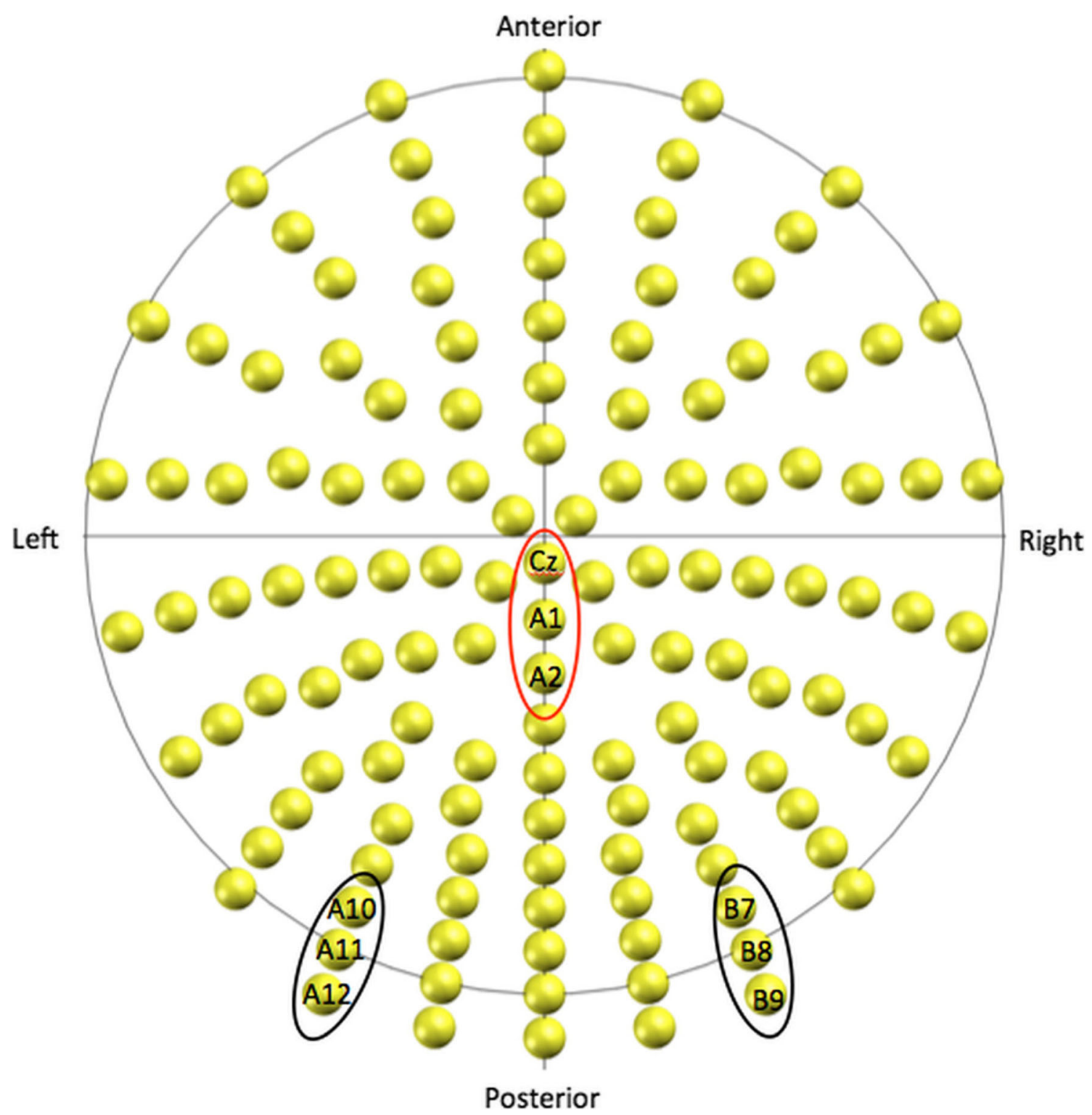

Fig. 3 Scalp distribution and names of 128 electrodes used in the EEG experiment. Black circles delimit the left and right ROIs (region of interests) used to compute the ERP analysis of the P1, the N190, and the P2. Red circle delimits central ROI used to compute LPC analysis (Colour figure online)

7.22, MSE $=129, \varepsilon=1, p<.01, \eta_{\mathrm{p}}^{2}=.16$, were significant, showing a greater preference for naked $(42 \pm$ 2.14) than clothed $(48 \pm 1.98)$ bodies, as well as for posterior $(41 \pm 1.95)$ than frontal $(39 \pm 2.06)$ views. The main effect of WHR was significant because of a greater preference for lower compared to higher ratios. A significant decrease in attractiveness was found between WHRs of 0.7 and $0.9, F(3,114)=185,21, M S E=22, \varepsilon$ $=.42, p<.0001, \eta_{\mathrm{p}}{ }^{2}=.83$; mean values: (0.9) $21.5 \pm$ $1.75<(0.8) 33 \pm 2<(0.6) 50 \pm 2.32<(0.7) 56.54 \pm$ $2.63 ; p \mathrm{~s}<.0001$. The interaction of WHRs $\times$ Nudity was also significant, $F(3,114)=55.52, M S E=26, \varepsilon=.64, p$ $<.02, \eta_{\mathrm{p}}{ }^{2}=.15$, because ratings were higher for naked than clothed bodies at ratios of 0.6 and 0.7 , but this was reversed for the 0.9 ratio. No effect was found for the
0.8 ratio between the two conditions $(33 \pm 2.84$ vs. $33 \pm$ $3.96 ; p=.45$; see Fig. 4 ).

\section{Electrophysiological study}

Performance on the oddball task was high, with a hit rate of $99.8 \%$ and a false alarm rate of $0.3 \%$, demonstrating that the participants were properly focused on the task.

\section{P1 component}

Latency The peak arose earlier for naked than clothed models, nudity: $F(1,18)=11.55, M S E=16, \varepsilon=1, p<.003$, $\eta_{\mathrm{p}}{ }^{2}=.4$; mean values: $139 \mathrm{~ms} \pm 1.79$ vs. $141 \mathrm{~ms} \pm 1.74$. 
Table 1 Summary of significant electrophysiological findings of the study

Tab. 1a - Amplitude

\begin{tabular}{|c|c|c|c|c|c|c|c|c|}
\hline component & \multicolumn{2}{|c|}{ P1 } & \multicolumn{2}{|c|}{ N190 } & \multicolumn{2}{|c|}{ P2 } & \multicolumn{2}{|c|}{ LPC } \\
\hline Factors/group & Male & Female & Male & Female & Male & Female & Male & Female \\
\hline View & & & \multicolumn{2}{|c|}{$\begin{array}{c}\mathrm{p}<.01 \\
\text { front }<\text { back } \\
\text { views }\end{array}$} & & & \multicolumn{2}{|c|}{$\begin{array}{c}\mathrm{p}<.01 \\
\text { front>back } \\
\text { views }\end{array}$} \\
\hline Nudity & & & \multicolumn{2}{|c|}{$\begin{array}{c}\mathrm{p}<.001 \\
\text { naked }<\text { clothed }\end{array}$} & \multicolumn{2}{|c|}{$\begin{array}{c}\mathrm{p}<.0001 \\
\text { naked }>\text { clothed }\end{array}$} & \multicolumn{2}{|c|}{$\begin{array}{c}\mathrm{p}<.001 \\
\text { naked }>\text { clothed }\end{array}$} \\
\hline WHR & $\begin{array}{c}p<.05 \\
0.7>(0.6, \\
0.8,0.9)\end{array}$ & & \multicolumn{2}{|c|}{$\begin{array}{c}p<.05 \\
0.6>(0.7,0.8 \\
0.9)\end{array}$} & & & \multicolumn{2}{|c|}{$\begin{array}{c}p<.05 \\
0.7>(0.6,0.8 \\
0.9)\end{array}$} \\
\hline ROI & & $\begin{array}{c}\mathrm{p}<.05 \\
\text { right }> \\
\text { left }\end{array}$ & & & \multicolumn{2}{|c|}{$\begin{array}{c}\mathrm{p}<.05 \\
\text { right }>\text { left }\end{array}$} & & \\
\hline
\end{tabular}

Tab. 1b - Latency

\begin{tabular}{|l|l|l|l|l|l|l|}
\hline \multicolumn{1}{|c|}{ component } & \multicolumn{2}{c|}{ P1 } & \multicolumn{2}{c|}{ N190 } & \multicolumn{2}{c|}{ P2 } \\
\hline factors /group & Male & Female & Male & Female & Male & Female \\
\hline Nudity & \multicolumn{2}{|c|}{$\begin{array}{c}\mathrm{p}<.01 \\
\text { naked }<\text { clothed }\end{array}$} & & & & \\
\hline View & & & & & & \\
\hline WHR & & & $\begin{array}{c}\text { p<.05 } \\
\text { left }>\text { right } \\
\text { leads at 0.7 } \\
\text { for males }\end{array}$ & & & \\
\hline ROI & & & & & \\
\hline WHR x ROI & & & & & \\
\hline
\end{tabular}

Note. Significant effects for (a) amplitudes and (b) latencies are indicated by dark highlighted squares for each component studied. The level of significance and the direction of the effects are indicated. Unmarked boxes indicate the absence of a significant effect

Amplitude The interaction of WHR $\times$ Group showed an increased amplitude for 0.7 WHR compared to the other ones only in the male group (see Fig. 5), $F(3,54)=$ $3.65, M S E=.9, \varepsilon=.9, p<.022, \eta_{\mathrm{p}}^{2}=.17$; mean values of male group: $5.7 \mu \mathrm{V} \pm .77$ vs. $5.3 \mu \mathrm{V} \pm .79$ (0.6), $5.4 \mu \mathrm{V} \pm .78(0.8), 5.4 \mu \mathrm{V} \pm .80(0.9), p \mathrm{~s}<.05$; mean values of female group: $6.26 \mu \mathrm{V} \pm .77(0.6), 6.16$ $\pm .77 \mu \mathrm{V}(0.7), 6.48 \mu \mathrm{V} \pm .78(0.8)$ and $6.38 \mu \mathrm{V} \pm .80$ $(0.9), p s>.05$. The female group significantly elicited greater amplitude on the right than left hemisphere, ROI $\times$ Group: $F(1,18)=7.36, M S E=32, \varepsilon=1, p<.014$, $\eta_{\mathrm{p}}{ }^{2}=.29$; mean values: $7.4 \mu \mathrm{V} \pm .85$ and $5.23 \mu \mathrm{V} \pm$ .83 , without any significant interaction with the male sample (as confirmed by the post hoc comparisons, all $p \mathrm{~s}>.1)$.

\section{N190 component}

Latency The 0.7 ratio elicited an earlier peak compared to the other ratios, as shown by a main effect of WHR, $F(3,54)=6.19, M S E=30, \varepsilon=.91, p<.002, \eta_{\mathrm{p}}^{2}=$ .26 ; mean values: $192 \mathrm{~ms} \pm 2.42$ vs. (0.6) $194 \mathrm{~ms} \pm 2.53$, 


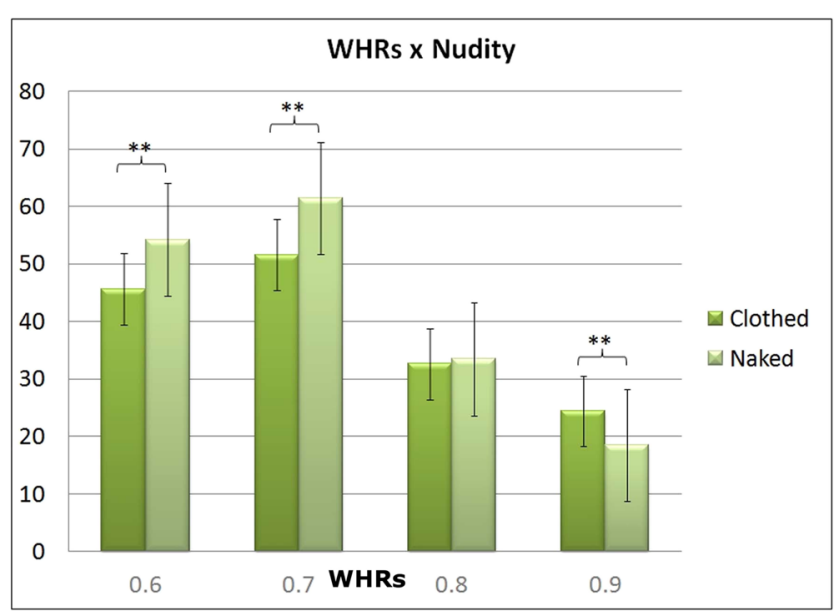

Fig. 4 WHR rating for naked and clothed bodies. Male and female groups show the same preferences when judging the WHRs of clothed and naked models. WHRs of 0.7 and 0.6 were considered more attractive when bodies were naked, whereas the clothed models were preferred at WHR ratios of $0.9 . * * p<.0001$

(0.8) $195 \mathrm{~ms} \pm 2.38,(0.9) 195 \mathrm{~ms} \pm 2.13 ; p \mathrm{~s}<.002$. However, the triple interaction of ROI $\times$ WHR $\times$ Group showed this effect is significant only over the left leads for the male group, $F(3,54)=3.26, M S E=$ $28, \varepsilon=.82, p<.04, \eta_{\mathrm{p}}^{2}=.15$.

Amplitude The main effect of the WHR factor, $F(3,54)=$ $3.98, M S E=1.2, \varepsilon=.88, p<.02, \eta_{\mathrm{p}}{ }^{2}=.18$, was significant due to a greater amplitude for 0.6 compared to all other ratios, mean values: (0.6) $-4.11 \mu \mathrm{V} \pm .61$, vs. (0.9) $-3.71 \mu \mathrm{V} \pm .66$,

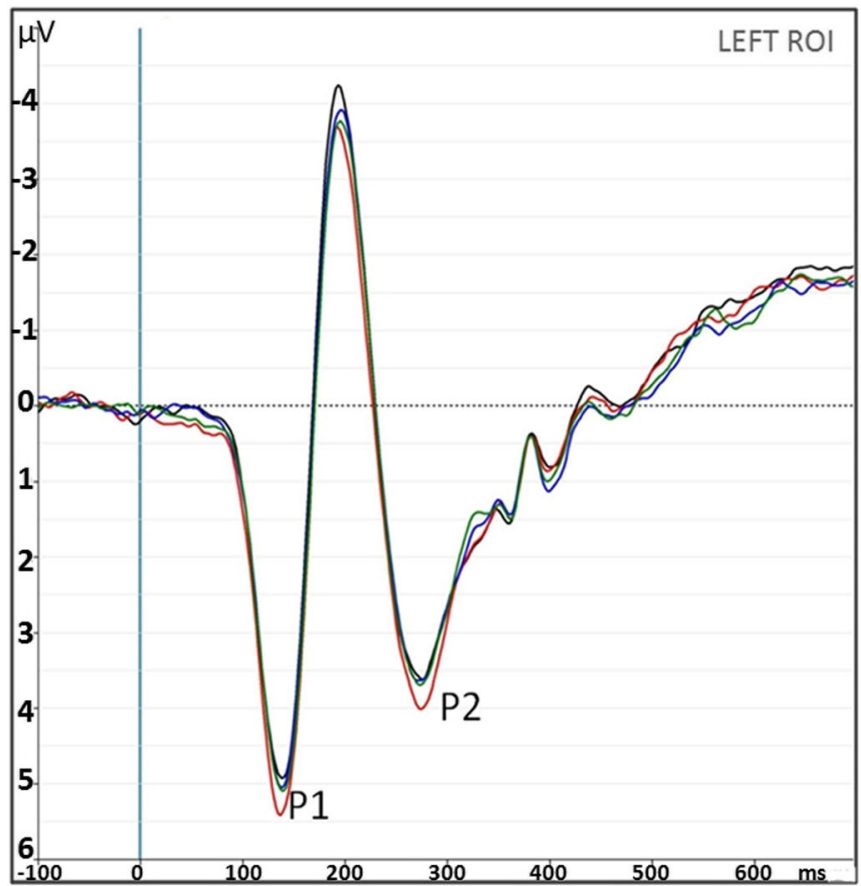

Fig. 5 ERPs illustrating the P1 and P2 in men. The P1 (120-160 ms) and P2 (250-310 ms) were computed by averaging the electrodes of the left and right ROIs for male participants. Only men showed an early effect for
(0.8) $-3.8 \mu \mathrm{V} \pm .61,(0.7)-3.83 \mu \mathrm{V} \pm .6 ; p \mathrm{~s}<.02$. Moreover, this component was more negative for front $(-4 \mu \mathrm{V} \pm .62)$ than back $(-3.7 \mu \mathrm{V} \pm .62)$ views, $F(1,18)=10.2, M S E=1.35, \varepsilon=$ $1, p<.005, \eta_{\mathrm{p}}{ }^{2}=.36$, and more negative for naked $(-4.7 \mu \mathrm{V} \pm$ $.65)$ than clothed $(-3 \mu \mathrm{V} \pm .6)$ bodies, $F(1,18)=88, M S E$ $=5.2, \varepsilon=1, p<.001, \eta_{\mathrm{p}}{ }^{2}=.83$, as shown in Fig. 6 .

\section{P2 component}

Latency No significant result was found.

Amplitude The positivity was significantly greater over the right than left ROIs, $F(1,18)=4.55, M S E=33.74, \varepsilon=1, p<$ $.05, \eta_{\mathrm{p}}{ }^{2}=.20$; mean values: $5.55 \mu \mathrm{V} \pm .44$ vs. $4.57 \mu \mathrm{V} \pm .46$, and for naked compared to clothed models, $F(1,18)=44.88$, $M S E=11, \varepsilon=1, p<.0001, \eta_{\mathrm{p}}{ }^{2}=.71$; mean values: $5.94 \mu \mathrm{V} \pm$ .43 vs. $4.18 \mu \mathrm{V} \pm .38$; see Fig. 7 .

\section{Late positive component (LPC)}

Men showed more positive LPCs than women as confirmed by the main effect of group, $F(1,18)=7.9$, $M S E=14.35, p<.02, \eta_{\mathrm{p}}^{2}=.30 ;$ mean values: $0.15 \mu \mathrm{V} \pm .44$ vs. $-1.34 \mu \mathrm{V} \pm .46$. Moreover, this component was more positive for naked than clothed bodies, nudity: $F(1,18)=23.23, M S E=.95, \varepsilon=1, p<.0002$, $\eta_{\mathrm{p}}^{2}=.56$; mean values: $-0.48 \mu \mathrm{V} \pm .23$ vs. $-1.57 \mu \mathrm{V} \pm$ .20 ; for front rather than back views, view: $F(1,18)=$

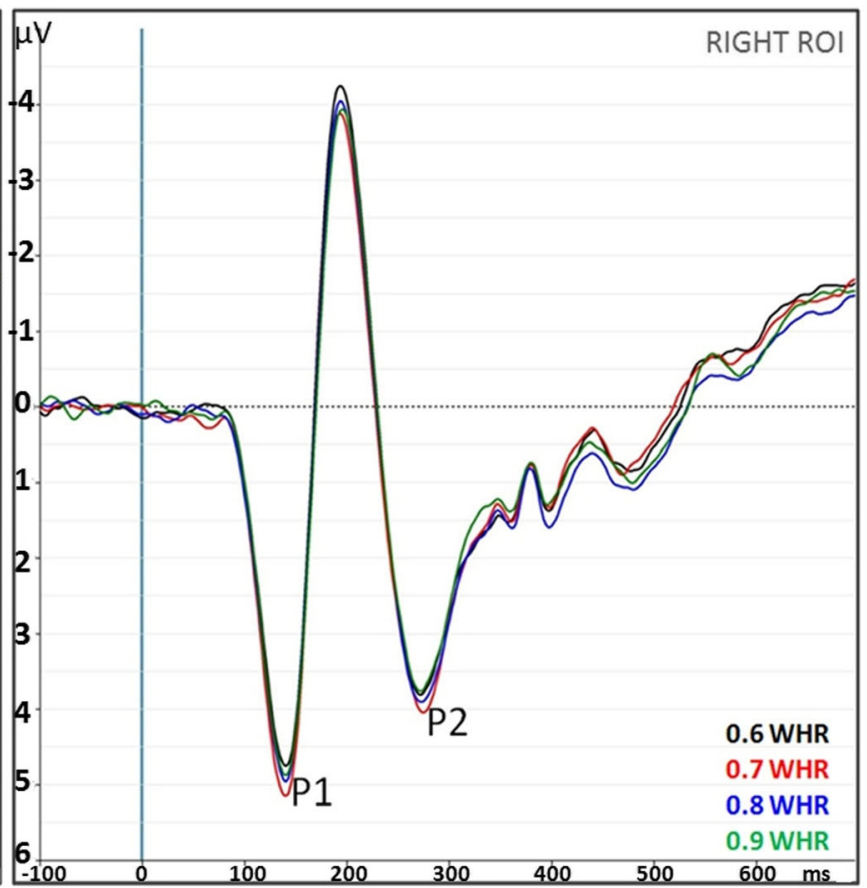

the 0.7 ratio (red line) compared to the other WHRs, independently of clothing or of view, at the P1 level (Colour figure online) 


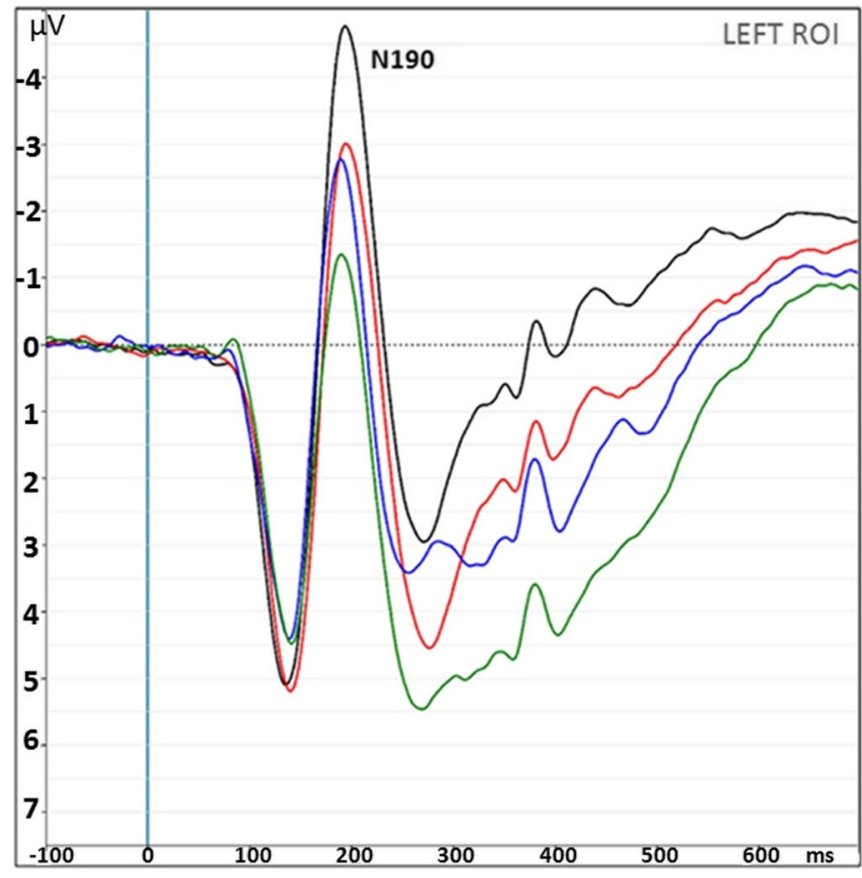

Fig. 6 N190 for naked and clothed bodies. A strong negative effect is observed between clothed and naked bodies at the N190 level for both groups of participants. Colours correspond to different conditions: naked

13.58, MSE $=.18, \varepsilon=1, p<.002, \eta_{\mathrm{p}}^{2}=.43$; mean values: $-0.21 \mu \mathrm{V} \pm .23$ vs. $-0.83 \mu \mathrm{V} \pm .22$; for 0.7 ratio compared with the other ones, WHR: $F(3,54)=4$, $M S E=.21, \varepsilon=.89, p<.02, \eta_{\mathrm{p}}^{2}=.18$; mean values: $-0.59 \mu \mathrm{V} \pm .21(0.7)$ vs. $-0.77 \mu \mathrm{V} \pm .20(0.9),-0.78 \mu \mathrm{V}$ $\pm .22(0.8)$ and $-0.82 \mu \mathrm{V} \pm .23(0.6), p \mathrm{~s}<.02$.

\section{Discussion}

This study addressed the dynamic aspects of visual processing of biologically relevant stimuli, in particular of the waist-to-hip ratio (WHR), an index of female body attractiveness. Behavioural results showed that the WHR affected the subjective evaluation of female body attractiveness by female as well as male viewers, with WHRs of 0.7 perceived as most attractive. The 0.6 and the 0.7 ratios were rated more highly in naked compared to clothed bodies, whereas this was not the case for the 0.8 ratio and was even reversed for 0.9 .

The electrophysiological results revealed early differences for the 0.7 ratio on the $\mathrm{P} 1$ in male viewers. In addition, the P1 peaked earlier for naked bodies in both men and women, suggesting that they are processed more rapidly than clothed ones. The N190 showed an effect of nudity with greater amplitudes for naked than clothed bodies, as well as an effect of viewpoint, with a stronger $\mathrm{N} 1$ for front than for back views, and finally an effect of WHR, with a greater response for ratios of 0.6 in both genders. In male viewers, a faster response was

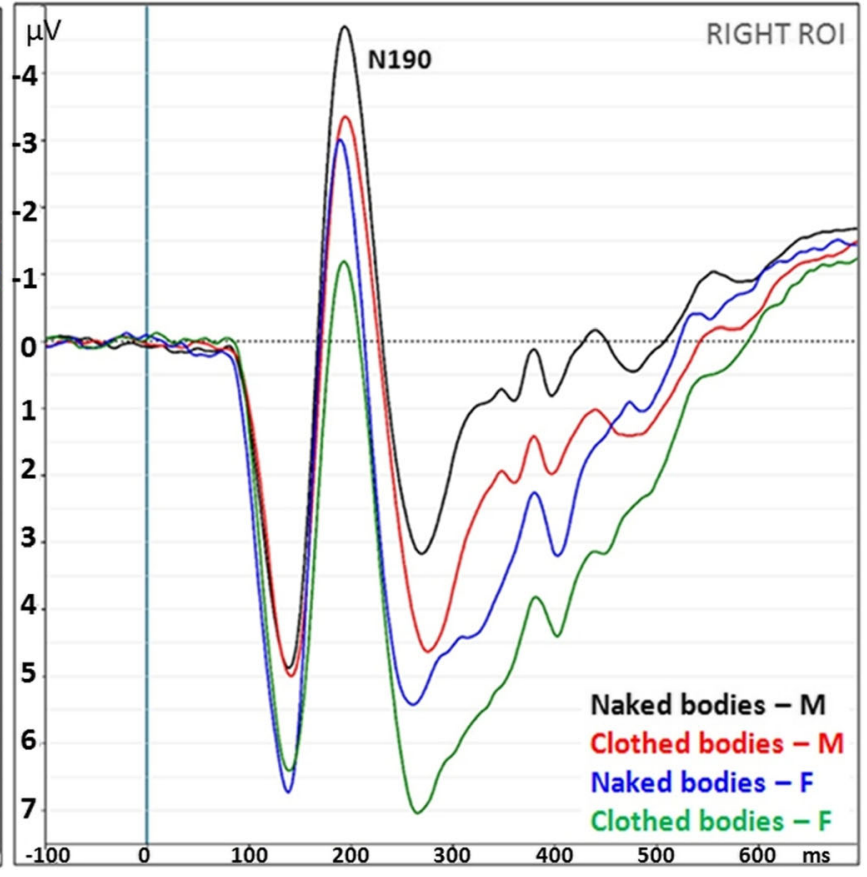

(black) and dressed (red) models for men; naked (blue) and dressed (green) models for women (Colour figure online)

found for the WHR of 0.7 over left electrodes. Naked bodies were also found to increase the $\mathrm{P} 2$ component in both groups of viewers. Lastly, the LPC, identified at $300-450 \mathrm{~ms}$, was greater in male than female participants overall. Furthermore, this component was less negative (more positive) for naked than clothed bodies, and for front views than back views in both participant groups. It was also stronger for WHRs of 0.7 in both male and female viewers.

Our behavioural results are in line with previous findings showing the expected preference of participants for lower WHRs (here 0.7 ) when evaluating physical attractiveness of female bodies presenting an apparently normal BMI (Dixson, Dixson, Li, \& Anderson, 2007; Dixson et al. 2010, 2011; Furnham et al., 2005; Singh, 1993; Singh \& Young, 1995).

The event-related potential data revealed the components anticipated for visual processing of body stimuli. Indeed, as mentioned, a category-sensitive ERP, the N190, has been described for bodies (Thierry et al., 2006). In our investigation, this N190 was also found to be sensitive to naked bodies. The sensitivity of the N1 component to naked bodies has only been reported very recently and suggests that these stimuli possess a high motivational and affective value. In one report (Hietanen \& Nummenmaa, 2011), male participants showed greater responses to female than male naked bodies, but no difference between female and male faces, suggesting a selective increase in activity for sexual features of the opposite sex in heterosexual participants. The current data show that female naked bodies generate a more powerful response in oppositesex, as well as same-sex heterosexual viewers. This is slightly 


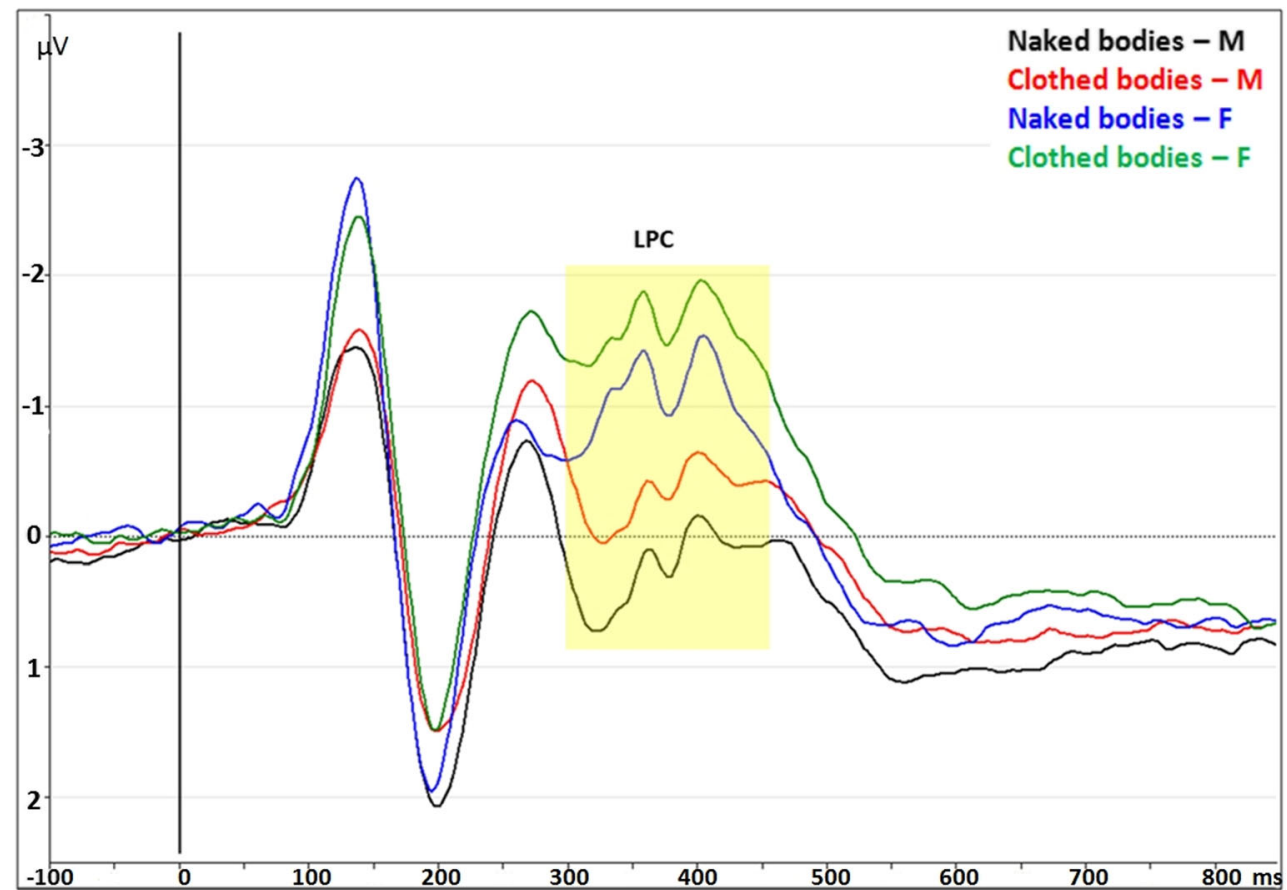

Fig. 7 LPC of male and female participants for naked and clothed bodies. Naked bodies produced more positive responses than clothed bodies over the central leads for both groups of participants. However, male participants produced overall a more positive ERP than female viewers. Traces are shown for the three central electrodes (see Fig. 3 for

at odds with the Hietanen and Nummenmaa's (2011) report, since the enhanced effect of nudity was not restricted to opposite sex models. However, a subsequent study appears to be more in line with our current findings. Legrand, Del Zotto, Tyrand, and Pegna (2013) demonstrated that the negativity was significantly enhanced in all participants when they viewed naked compared to clothed bodies, independently of the viewer's gender. However, the opposite-sex difference was observed under subliminal conditions, suggesting that the effect may vary according to the extent of voluntary processing of the stimuli. In Hietanen and Nummenmaa's (2011) experiment, images were presented for $3 \mathrm{~s}$, while in our study, viewing conditions were more limited, with presentations of $250 \mathrm{~ms}$, offering a possible explanation for the difference.

Nevertheless, the N1 response for bodies appears to be enhanced by the sexual content of the stimulus. This interpretation seems to be further corroborated by the fact that front views (and thus the visibility of the primary sexual features) also enhanced the N1 in our paradigm.

Our study also sheds light on the spatiotemporal dynamics of the cognitive processing underlying preferences for such stimuli. Based on the electrophysiological results, it is evident that the type of WHR ratio plays an important role in producing an interest in heterosexual men (and women). Although behavioural assessments were similar in both genders, the ERP results were clearly different. Women were still sensitive to WHRs in evaluating female body attractiveness, but the electrode placement): colours indicate naked (black) and dressed (red) models viewed by men, and naked (blue) and clothed (green) models viewed by women. Yellow highlighted box indicates the time period in which the LPC was computed (Colour figure online)

ERP analyses revealed different patterns of cerebral activation. Specifically, the P1 component was sensitive to the 0.7 WHR only in men, whereas the 0.7 WHR heightened the later LPC component in both men and women. Thus, the sensibility to this specific body feature appears evident and marked in heterosexual men. The P1 is thought to represent a marker of early automatic attention for biologically relevant visual stimuli. The current findings suggest that human bodies can be processed very early in time, especially when they represent biologically relevant cues. In other studies, a greater amplitude of the $\mathrm{P} 1$ component was also found for images of nude compared to clothed women, or compared with women practicing daily activities and extreme sports (Kuhr, Schomberg, Gruber, \& Quirin, 2013). Kuhr and colleagues (2013) suggested that positive as well as negative stimuli might affect very early components when they are appetitive. In their experiment, performed only with men, they found an increased positivity peaking at $130 \mathrm{~ms}$ after the presentation of arousing photos of erotic, nude women compared to photos of attractive, dressed bodies, extreme sport scenes, or daily activities. Our research shows very similar results. Indeed, we observed that specific traits have the potential to make the human body appetitive, and this can be processed very early in time. Moreover, this aspect seems to have an advantage on other appealing stimuli, such as naked bodies. In line with Kuhr and colleagues (2013), we therefore hypothesize that the WHR indicates that a female body is healthy and fertile, consequently increasing 
sexual desirability. The early response for attractive bodies, alongside sexual or alimentary objects, could be seen as reflecting and evolutionary advantage in the context of conspecific competition for mate choice and reproductive success. Previously, Briggs and Martin (2009) designated appetence - the craving for a positively valenced object (Craig 1917) — as a third dimension, independent of valence and arousal, associated with distinct neural responses. In our case, body appetence due to the different WHRs is reflected by an early component over extrastriate visual areas, the P1, which must therefore constitute the electrophysiological index of this sexual trait in humans.

The N190 yielded a different pattern of results and showed no difference in sensitivity between men and women for the 0.7 ratio. However, sensitivity to WHR was nonetheless observed. In this specific case, both male and female viewers presented a greater $\mathrm{N} 1$ to the 0.6 ratio compared to the others. ERP studies of facial attractiveness have reported the presence of P1, N1 and P2 modulations. Some researchers have provided evidence that the $\mathrm{P} 2$ is the earliest component sensitive to attractive and unattractive faces (Chen et al., 2012; Van Hooff, Crawford, \& van Vugt, 2011). Others have reported earlier modulations. Halit, de Haan, and Johnson (2000) observed that natural, unattractive faces produced a larger N170 component. However, this was found only for natural faces judged to be unattractive, but not for faces that were artificially modified, making them not only unattractive, but also atypical. By contrast, artificially modified (stretched) unattractive faces affected P1 and P2 amplitudes, rather than the N170. Along similar lines, another study (Trujillo, Jankowitsch, \& Langlois, 2014) observed a smaller N170 for more attractive, as well as averaged faces, compared to less attractive faces. This suggested that the N170 might in fact be sensitive essentially to the typicality of a face (i.e. variations of features across individuals), corroborating the view that prototypicality and attractiveness are linked, with both affecting the same electrophysiological component, and arguing in favour of prototypicality detector rather than a fertility detector.

This evidence points to a potential limitation of our study due to the use of computer-generated bodies. This procedure could have limited the ecologically validity of the stimuli and, as was observed for faces (Halit et al., 2000), could be responsible for the early P1 effect for artificially modified stimuli. Indeed, the modifications that were applied to the bodies did not take into account elements such as breast size, actual BMI, skin quality, and so forth. This may have given an artificial appearance to the bodies and could have produced unwanted effects. However, the P1 was enhanced only for male viewers that would argue against an effect due solely to an artificial appearance. In addition, the findings in the behavioural task are compatible with those carried out with real photographs, confirming that the stimuli were nevertheless evaluated in a similar way, and thus, to a certain extent, as real bodies. On the other hand, the advantage of computer-generated images resides in the fact that low-level visual characteristics (luminance, posture, background, and colour) can be precisely controlled across conditions, allowing us to interpret any early components in terms of the behavioural relevance of the stimuli, rather than their elementary visual features. Preceding studies have also shown that the P1 component is more sensitive to nonspatial features in the attended location (Zani \& Proverbio, 2012); to certain primary structural features (e.g. contours) of faces (Olivares, Iglesias, Saavedra, TrujilloBarreto, \& Valdés-Sosa, 2015), during passive viewing of stimuli (Warbrick, Arrubla, Boers, Neuner, \& Shah, 2013); or to the social meaning signaled by the direction of biological motion (Pegna, Gehring, Meyer, \& Del Zotto, 2015). In our case, both components show a clear effect for the most attractive WHR when stimuli are presented centrally at the attended, and only in heterosexual men presented. The stronger response appears most likely due to their high biologically significance and value, which are relevant for mating behaviour. Based on this, it seems plausible that evolutionary selection has developed human cognitive mechanisms to recognize specific physical traits as potential indices of health and fertility (Dixson et al. 2011; Furnham, Dias, \& McClelland, 1998), contributing in a significant manner to mate choice (Dixson et al., 2011; Grammer, Fink, Møller, \& Thornhill, 2003).

Finally, our data revealed a heightened LPC for the most attractive (0.7) WHR. This is in keeping with findings reporting a greater LPC for attractive faces (Chen et al., 2012; Johnston \& Oliver-Rodriguez, 1997; Marzi \& Viggiano, 2010; Oliver-Rodríguez, Guan, \& Johnston, 1999; Schacht, Werheid, \& Sommer, 2008; Werheid, Schacht, \& Sommer, 2007; Zhang et al., 2011). For example, Johnston and Oliver-Rodriguez (1997) observed an LPC in male viewers viewing female (but not male) faces that were manipulated to enhance attractiveness. The results revealed that the LPC, which showed a greater parietal than frontal scalp distribution, reflected the beauty rating of a female faces and not just attractiveness. In addition, they demonstrated that the modification of proportions producing facial traits of masculinity or femininity enhanced the beauty ratings as expected, along with the LPCs to female, but not male faces. Similarly, Oliver-Rodriguez and colleagues (1999) found that the average P300 and the mean subjective ratings were correlated, indicating that this late component was linked to the perceived degree of attractiveness. Of particular interest to our study, the authors also observed a stronger P300 or LPC for male viewers compared to female viewers, as observed in our results. Based on their interpretation of this phenomenon with faces, we would argue that if the LPC reflects the attractiveness of a stimulus for the participant, it is clear that the response must be greater for heterosexual male viewers as only female naked and clothed models were presented and a preference is to be expected. However, despite the lower 
emotional value of the stimuli for heterosexual female participants, ratings were similar between female and male viewers, reflecting as a similar value on the LRP for naked versus clothed bodies and for 0.7 WHRs versus the other ratios.

Another potential limitation of this study is that the behavioural and EEG measures were not collected from the same set of participants. We were therefore unable to investigate any direct correlation between the subjective evaluation of the bodies and the ERP components. This could be carried out in future research as this approach could strengthen the actual interpretation.

In line with other reports (Cornelissen et al., 2009; Fan et al., 2007; Tovée \& Cornelissen, 2001), our findings therefore support the mate selection theory, which underscores the important role of attractiveness in social and reproductive life, especially for women. They are more meticulous than men in maintaining their level of desirability, probably to maximize the own reproductive success. Being focused on opposite sex mates with the same level of attractiveness, they avoid an engagement of resources, energy, and time with partners of different levels and, consequently increase the likelihood of mating success. It is important to emphasise that the WHR is an index of physical symmetry and good health. In fact, premature births, psychosis, consanguinity and mental retardation are associated with bodily asymmetry in humans. The choice of partners with symmetric features is thus likely to indicate higher genetic quality and subsequent benefits to the offspring (Buggio et al., 2012). In the case of WHRs, the 0.60.7 ratio appears to reflect the ideal range for reproductive success. The sum of evidence thus shows that early electrical activity of the human brain responds to this ideal ratio, revealing that mate selection affects cognitive dynamics within the first $200 \mathrm{~ms}$ of visual processing.

Acknowledgements This investigation was supported by the Swiss National Science Foundation Grant No. 320030-144187. We are grateful to Sophie Nussbaum and Chiara Chillà who provided diligent assistance with EEG recording and analysis.

\section{References}

Aharon, I., Etcoff, N., Ariely, D., Chabris, C. F., O'Connor, E., \& Breiter, H. C. (2001). Beautiful faces have variable reward value: FMRI and behavioral evidence. Neuron, 32(3), 537-551.

Bohler, H., Jr., Mokshagundam, S., \& Winters, S. J. (2010). Adipose tissue and reproduction in women. Fertility and Sterility, 94(3), $795-825$.

Briggs, K. E., \& Martin, F. H. (2009). Affective picture processing and motivational relevance: Arousal and valence effects on ERPs in an oddball task. International Journal of Psychophysiology, 72(3), 299-306.

Buggio, L., Vercellini, P., Somigliana, E., Viganò, P., Frattaruolo, M. P., \& Fedele, L. (2012). "You are so beautiful": Behind women's attractiveness towards the biology of reproduction: A narrative review. Gynecological Endocrinology, 28(10), 753-757.
Chen, J., Zhong, J., Zhang, Y., Li, P., Zhang, A., Tan, Q., \& Li, H. (2012). Electrophysiological correlates of processing facial attractiveness and its influence on cooperative behavior. Neuroscience Letters, 517(2), 65-70.

Cornelissen, P. L., Hancock, P. J. B., Kiviniemi, V., George, H. R., \& Tovée, M. J. (2009). Patterns of eye movements when male and female observers judge female attractiveness, body fat and waistto-hip ratio. Evolution and Human Behavior, 30(6), 417-428.

Craig, W. (1917). Appetites and aversions as constituents of instincts. Proceedings of the National Academy of Sciences of the United States of America, 3(12), 685-688.

Cremonini, E., Bonaccorsi, G., Bergamini, C. M., Castaldini, C., Ferrazzini, S., Capatti, A., ... Cervellati, C. (2013). Metabolic transitions at menopause: In post-menopausal women the increase in serum uric acid correlates with abdominal adiposity as assessed by DXA. Maturitas, 75(1), 62-66.

Currie, T. E., \& Little, A. C. (2009). The relative importance of the face and body in judgments of human physical attractiveness. Evolution and Human Behavior, 30(6), 409-416.

Dixson, B. J., Dixson, A., Bishop, P., \& Parish, A. (2009). Human physique and sexual attractiveness in men and women: A New ZealandU.S. comparative study. Archives of Sexual Behavior, 39(3), 798806.

Dixson, B. J., Dixson, A. F., Li, B., \& Anderson, M. J. (2007). Studies of human physique and sexual attractiveness: Sexual preferences of men and women in China. American Journal of Human Biology, 19(1), 88-95.

Dixson, B. J., Dixson, A., Morgan, B., \& Anderson, M. (2007). Human physique and sexual attractiveness: Sexual preferences of men and women in Bakossiland, Cameroon. Archives of Sexual Behavior, 36(3), 369-375.

Dixson, B. J., Grimshaw, G., Linklater, W., \& Dixson, A. (2010). Eye tracking of men's preferences for female breast size and areola pigmentation. Archives of Sexual Behavior, 40(1), 51-58.

Dixson, B. J., Grimshaw, G. M., Linklater, W. L., \& Dixson, A. F. (2011). Eye-tracking of men's preferences for waist-to-hip ratio and breast size of women. Archives of Sexual Behavior, 40(1), 43-50.

Fan, J., Dai, W., Qian, X., Chau, K. P., \& Liu, Q. (2007). Effects of shape parameters on the attractiveness of a female body. Perceptual and Motor Skills, 105(1), 117-132.

Furnham, A., Dias, M., \& McClelland, A. (1998). The role of body weight, waist-to-hip ratio, and breast size in judgments of female attractiveness. Sex Roles, 39(3/4), 311-326.

Furnham, A., Mistry, D., \& McClelland, A. (2004). The influence of age of the face and the waist to hip ratio on judgements of female attractiveness and traits. Personality and Individual Differences, 36(5), 1171-1185.

Furnham, A., Petrides, K. V., \& Constantinides, A. (2005). The effects of body mass index and waist-to-hip ratio on ratings of female attractiveness, fecundity, and health. Personality and Individual Differences, 38(8), 1823-1834.

Gangestad, S. W., Thornhill, R., \& Yeo, R. A. (1994). Facial attractiveness, developmental stability, and fluctuating asymmetry. Ethology and Sociobiology, 15(2), 73-85.

Grammer, K., Fink, B., Møller, A. P., \& Thornhill, R. (2003). Darwinian aesthetics: Sexual selection and the biology of beauty. Biological Reviews, 78(3), 385-407.

Grammer, K., \& Thornhill, R. (1994). Human (Homo sapiens) facial attractiveness and sexual selection: The role of symmetry and averageness. Journal of Comparative Psychology, 108(3), 233-242.

Halberstadt, J., \& Rhodes, G. (2000). The attractiveness of nonface averages: Implications for an evolutionary explanation of the attractiveness of average faces. Psychological Science, 11(4), 285-289.

Halberstadt, J., \& Rhodes, G. (2003). It's not just average faces that are attractive: Computer-manipulated averageness makes birds, fish, 
and automobiles attractive. Psychonomic Bulletin \& Review, 10(1), 149-156.

Halit, H., de Haan, M., \& Johnson, M. H. (2000). Modulation of eventrelated potentials by prototypical and atypical faces. NeuroReport, 11(9), 1871-1875.

Han, C., Hahn, A. C., Fisher, C. I., Debruine, L. M., \& Jones, B. C. (2016). Women's facial attractiveness is related to their body mass index but not their salivary cortisol. American Journal of Human Biology, 28(3), 352-355.

Henss, R. (1995). Waist-to-hip ratio and attractiveness. Replication and extension. Personality and Individual Differences, 19(4), 479-488.

Henss, R. (2000). Waist-to-hip ratio and female attractiveness: Evidence from photographic stimuli and methodological considerations. Personality and Individual Differences, 28(3), 501-513.

Hietanen, J. K., \& Nummenmaa, L. (2011). The naked truth: The face and body sensitive N170 response is enhanced for nude bodies. PLoS ONE, 6(11), e24408.

Holliday, I. E., Longe, O. A., Thai, N. J., Hancock, P. J. B., \& Tovée, M. J. (2011). BMI not WHR modulates BOLD fMRI responses in a subcortical reward network when participants judge the attractiveness of human female bodies. PLoS ONE, 6(11), e27255.

Jasienska, G., Ziomkiewicz, A., Ellison, P. T., Lipson, S. F., \& Thune, I. (2004). Large breasts and narrow waists indicate high reproductive potential in women. Proceedings: Biological Sciences, 271(1545), 1213-1217.

Johnston, V. S., \& Oliver-Rodriguez, J. C. (1997). Facial beauty and the late positive component of event-related potentials. The Journal of Sex Research, 34(2), 188-198.

Jokela, M. (2009). Physical attractiveness and reproductive success in humans: Evidence from the late 20(th) century United States. Evolution and Human Behavior: Official Journal of the Human Behavior and Evolution Society, 30(5), 342-350.

Kedia, G., Mussweiler, T., Mullins, P., \& Linden, D. E. J. (2014). The neural correlates of beauty comparison. Social Cognitive and Affective Neuroscience, 9(5), 681-688.

Kinsey, A. C., Pomeroy, W. R., \& Martin, C. E. (2003). Sexual behavior in the human male. American Journal of Public Health, 93(6), 894 898

Kuhr, B., Schomberg, J., Gruber, T., \& Quirin, M. (2013). Beyond pleasure and arousal: Appetitive erotic stimuli modulate electrophysiological brain correlates of early attentional processing. NeuroReport, 24(5), 246-250.

Langlois, J. H., \& Roggman, L. A. (1990). Attractive faces are only average. Psychological Science, 1(2), 115-121.

Legrand, L. B., Del Zotto, M., Tyrand, R., \& Pegna, A. J. (2013). Basic instinct undressed: Early spatiotemporal processing for primary sexual characteristics. PLoS ONE, 8(7), e69726.

Marlowe, F., Apicella, C., \& Reed, D. (2005). Men's preferences for women's profile waist-to-hip ratio in two societies. Evolution and Human Behavior, 26(6), 458-468.

Marlowe, F., \& Wetsman, A. (2001). Preferred waist-to-hip ratio and ecology. Personality and Individual Differences, 30(3), 481-489.

Marzi, T., \& Viggiano, M. P. (2010). When memory meets beauty: Insights from event-related potentials. Biological Psychology, 84(2), 192-205.

Mealey, L., Bridgstock, R., \& Townsend, G. C. (1999). Symmetry and perceived facial attractiveness: A monozygotic co-twin comparison. Journal of Personality and Social Psychology, 76(1), 151-158.

Oldfield, R. C. (1971). The assessment and analysis of handedness: The Edinburgh Inventory. Neuropsychologia, 9, 97-113.

Olivares, E. I., Iglesias, J., Saavedra, C., Trujillo-Barreto, N. J., \& ValdésSosa, M. (2015). Brain signals of face processing as revealed by event-related potentials. Behavioural Neurology, 2015. doi:10. $1155 / 2015 / 514361$
Oliver-Rodríguez, J. C., Guan, Z., \& Johnston, V. S. (1999). Gender differences in late positive components evoked by human faces. Psychophysiology, 36(2), 176-185.

Pazhoohi, F., \& Liddle, J. R. (2012). Identifying feminine and masculine ranges for waist-to-hip ratio. Journal of Social, Evolutionary, and Cultural Psychology, 6(2), 227-232.

Peelen, M. V., \& Downing, P. E. (2007). The neural basis of visual body perception. Nature Reviews Neuroscience, 8(8), 636-648.

Pegna, A. J., Gehring, E., Meyer, G., \& Del Zotto, M. (2015). Direction of biological motion affects early brain activation: A link with social cognition. PLoS ONE, 10(6), e0131551.

Penton-Voak, I. S., Jones, B. C., Little, A. C., Baker, S., Tiddeman, B., Burt, D. M., \& Perrett, D. I. (2001). Symmetry, sexual dimorphism in facial proportions and male facial attractiveness. Proceedings of the Royal Society of London. Series B: Biological Sciences, 268(1476), 1617-1623.

Perrett, D. I., Burt, D. M., Penton-Voak, I. S., Lee, K. J., Rowland, D. A., \& Edwards, R. (1999). Symmetry and human facial attractiveness. Evolution and Human Behavior, 20(5), 295-307.

Perrett, D. I., Lee, K. J., Penton-Voak, I., Rowland, D., Yoshikawa, S., Burt, D. M., ... S. Akamatsu (1998). Effects of sexual dimorphism on facial attractiveness. Nature, 394(6696), 884-887.

Platek, S. M., \& Singh, D. (2010). Optimal waist-to-hip ratios in women activate neural reward centers in men. PLOS ONE, 5(2), e9042.

Principe, C. P., \& Langlois, J. H. (2012). Shifting the prototype: Experience with faces influences affective and attractiveness preferences. Social Cognition, 30(1), 109-120.

Probst, F., Bobst, C., \& Lobmaier, J. S. (2016). Testosterone-to-oestradiol ratio is associated with female facial attractiveness. The Quarterly Journal of Experimental Psychology, 69(1), 89-99.

Puts, D. A., Bailey, D. H., Cárdenas, R. A., Burriss, R. P., Welling, L. L. M., Wheatley, J. R., \& Dawood, K. (2013). Women's attractiveness changes with estradiol and progesterone across the ovulatory cycle. Hormones and Behavior, 63(1), 13-19.

Roberts, S. C., Havlicek, J., Flegr, J., Hruskova, M., Little, A. C., Jones, B. C., ... Petrie, M. (2004). Female facial attractiveness increases during the fertile phase of the menstrual cycle. Proceedings of the Royal Society of London. Series B: Biological Sciences, 271(Suppl. 5), S270-S272.

Rolls, E. T., \& Grabenhorst, F. (2008). The orbitofrontal cortex and beyond: From affect to decision-making. Progress in Neurobiology, 86(3), 216-244.

Schacht, A., Werheid, K., \& Sommer, W. (2008). The appraisal of facial beauty is rapid but not mandatory. Cognitive, Affective, \& Behavioral Neuroscience, 8(2), 132-142.

Schwarzlose, R. F., Baker, C. I., \& Kanwisher, N. (2005). Separate face and body selectivity on the fusiform gyrus. The Journal of Neuroscience, 25(47), 11055-11059.

Singh, D. (1993). Adaptive significance of female physical attractiveness: Role of waist-to-hip ratio. Journal of Personality and Social Psychology, 65(2), 293-307.

Singh, D. (2002). Female mate value at a glance: Relationship of waist-tohip ratio to health, fecundity and attractiveness. Neuroendocrinology Letters, 23(Special issue, Suppl.4).

Singh, D., \& Young, R. K. (1995). Body weight, waist-to-hip ratio, breasts, and hips: Role in judgments of female attractiveness and desirability for relationships. Ethology and Sociobiology, 16(6), 483-507.

Spicer, K. R., \& Platek, S. M. (2010). Curvaceous female bodies activate neural reward centers in men. Communicative \& Integrative Biology, 3(3), 282-283.

Stekelenburg, J. J., \& Gelder, B. D. (2004). The neural correlates of perceiving human bodies: An ERP study on the body-inversion effect. NeuroReport, 15(5), 777-780. 
Swami, V., Caprario, C., Tovée, M. J., \& Furnham, A. (2006). Female physical attractiveness in Britain and Japan: A cross-cultural study. European Journal of Personality, 20(1), 69-81.

Swami, V., \& Furnham, A. (2009). Big and beautiful: Attractiveness and health ratings of the female body by male 'fat admirers'. Archives of Sexual Behavior, 38(2), 201-208.

Swami, V., Neto, F., Tovée, M. J., \& Furnham, A. (2007). Preferences for female body weight and shape in three European countries. European Psychologist, 12(3), 220-228.

Swami, V., \& Tovée, M. J. (2005). Female physical attractiveness in Britain and Malaysia: A cross-cultural study. Body Image, 2(2), 115-128.

Swami, V., \& Tovée, M. J. (2006). The influence of body mass index on the physical attractiveness preferences of feminist and nonfeminist heterosexual women and lesbians. Psychology of Women Quarterly, 30(3), 252-257.

Thierry, G., Pegna, A. J., Dodds, C., Roberts, M., Basan, S., \& Downing, P. (2006). An event-related potential component sensitive to images of the human body. NeuroImage, 32(2), 871-879.

Tovée, M. J., \& Cornelissen, P. L. (2001). Female and male perceptions of female physical attractiveness in front-view and profile. British Journal of Psychology, 92(2), 391-402.

Tovée, M. J., Maisey, D. S., Emery, J. L., \& Cornelissen, P. L. (1999). Visual cues to female physical attractiveness. Proceedings of the Royal Society of London. Series B: Biological Sciences, 266(1415), 211-218.

Trujillo, L. T., Jankowitsch, J. M., \& Langlois, J. H. (2014). Beauty is in the ease of the beholding: A neurophysiological test of the averageness theory of facial attractiveness. Cognitive, Affective, \& Behavioral Neuroscience, 14(3), 1061-1076.

Van Hooff, J. C., Crawford, H., \& van Vugt, M. (2011). The wandering mind of men: ERP evidence for gender differences in attention bias towards attractive opposite sex faces. Social Cognitive and Affective Neuroscience, 6(4), 477-485.

Warbrick, T., Arrubla, J., Boers, F., Neuner, I., \& Shah, N. J. (2013). Attention to detail: Why considering task demands is essential for single-trial analysis of BOLD correlates of the visual P1 and N1. Journal of Cognitive Neuroscience, 26(3), 529-542.

Werheid, K., Schacht, A., \& Sommer, W. (2007). Facial attractiveness modulates early and late event-related brain potentials. Biological Psychology, 76(1/2), 100-108.

Winkielman, P., Halberstadt, J., Fazendeiro, T., \& Catty, S. (2006). Prototypes are attractive because they are easy on the mind. Psychological Science, 17(9), 799-806.

Winston, J. S., O'Doherty, J., Kilner, J. M., Perrett, D. I., \& Dolan, R. J. (2007). Brain systems for assessing facial attractiveness. Neuropsychologia, 45(1), 195-206.

Yu, D. W., \& Shepard, G. H. (1998). Is beauty in the eye of the beholder? Nature, 396(6709), 321-322.

Zani, A., \& Proverbio, A. M. (2012). Is that a belt or a snake? object attentional selection affects the early stages of visual sensory processing. Behavioral and Brain Functions, 8(1), 1-19.

Zhang, Y., Kong, F., Chen, H., Jackson, T., Han, L., Meng, J., ... Najam ul Hasan, A. (2011). Identifying cognitive preferences for attractive female faces: An event-related potential experiment using a study-test paradigm. Journal of Neuroscience Research, 89(11), 1887-1893. 